\title{
A STUDY ON FORCE-DISPLACEMENT-BASED SEIS- MIC DESIGN OF SINGLE-COLUMN RC PIERS
}

\author{
Kiyoshi HIRAO $^{1}$, Yukinori SAKAGAMI ${ }^{2}$, Yoshifumi NARIYUKI ${ }^{3}$ \\ and Tsutomu SAWADA ${ }^{4}$ \\ ${ }^{1}$ Fellow of JSCE, Dr. Eng. Professor, Dept. of Civil Eng. University of Tokushima \\ (2-1, Minamijosanjima-cho, Tokushima 770-8506, Japan) \\ E-mail: cvsteng@ce.tokushima-u.ac.jp \\ ${ }^{2}$ Member of JSCE, M. Eng., Research Engineer, Hitachi Zosen Corporation \\ (1-7-89, Nanko-kita, Suminoe-ku, Osaka 559-8559, Japan) \\ ${ }^{3}$ Member of JSCE, Dr. Eng., Associate Professor, Dept. of Civil Eng. University of Tokushima \\ (2-1, Minamijosanjima-cho, Tokushima 770-8506, Japan) \\ ${ }^{4}$ Member of JSCE, Dr. Eng. Professor, Dept. of Civil Eng. University of Tokushima \\ (2-1, Minamijosanjima-cho, Tokushima 770-8506, Japan)
}

\begin{abstract}
As a fundamental study to develop a force-displacement-based seismic design of RC piers, the acceleration-displacement response spectrum (ADRS) of SDOF systems with elastic-plastic bilinear restoring force characteristics is obtained by inelastic response analysis, provided that the value of modified Park-Ang damage index $D$ of a SDOF system equals the required value $D_{r}=0.4$ that almost correspond to the repairable limit of the system. The regression equation of ADRS is derived and applied to a force-displacement-based seismic design of a single-column RC pier. The design results by the proposed method are compared with the ones by the ductility design method of Japanese Specifications.
\end{abstract}

Key Words: acceleration-displacement response spectrum, modified Park-Ang damage index, force-displacement-based seismic design, single-column RC pier

\section{INTRODUCTION}

Presently, the so called "force-based seismic design method", as represented by the Japanese Design Specifications of Highway Bridges, Part V Seismic Design ${ }^{1)}$ (hereafter referred to as the Japanese Specifications), is the main method of the seismic design of a structure. In the force-based design method, the design seismic force of a target structure is specified on the basis of the acceleration response spectrum. The structure is then designed to maintain its serviceability securely in the event of moderate ground motions with high probability of occurrence (hereafter referred to as the Level 1 earthquake motions), and to ensure the required lateral capacity against the extreme ground motions with low probability of occurrence (hereafter referred to as the Level 2 earthquake motions).

In the force-based seismic design method, however, there are some points that should be improved. For example, the design procedure to verify whether the response displacement ductility factor of a designed structure is close to the allowable one has not been stipulated, despite the fact that the design seismic force of a target structure is calculated by using the allowable displacement ductility factor. Also it is well known that the force (stress) produced in a structure due to some loads is essentially dependent on the deformation (strain) of the structure. Consequently the degree of damage of a structure due to earthquake motion, that is, the various required performance levels of the structure, are described more easily and more clearly by the response value of deformation than that of force. Recently, therefore, a new seismic design method by the use of spectral displacement (deformation), which is more closely related to the seismic safety of the structure under severe earthquake motions, namely the displacement-based design method using the displacement response spectrum, has been proposed and examined ${ }^{2), 3), 4)}$. However, the relation between the current force-based method and the new displacement-based method has yet to be made clear. 


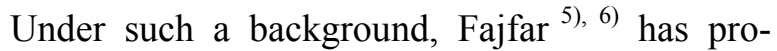
posed a modified capacity spectrum method, originally proposed by Freeman et al, in order to more easily verify the safety of a structure subjected to severe earthquake motions by comparing the acceleration displacement response spectrum (hereafter referred to as the ADRS) obtained by inelastic response analysis, with the capacity spectrum of the structure. This method is considered to be useful to develop a more rational seismic design method of a structure in the future ${ }^{7)}$ because the method makes it possible to verify the seismic safety of a structure from both the force and the displacement.

In this study, therefore, as a fundamental study for applying this new seismic design method (verifying method of seismic safety) to a road bridge in Japan by use of the ADRS, the authors first simulate seventy-two earthquake motions so that the acceleration response spectra of the simulated motions agreed well with the ones for the Level 2 earthquake motions prescribed in the Japanese Specifications. The ADRS for bi-linear SDOF systems with elastic-perfectly plastic restoring force characteristics, which is used in the ductility design method of the Japanese Specifications, is obtained by the inelastic seismic response analysis inputting the simulated earthquake motions. Here the ADRS is a damage controlled spectrum because the ADRS is obtained with the condition that the value of modified Park-Ang damage index $D$ of the SDOF system is equal to the required value, $D_{r}=0.4$ that almost correspond with the repairable limit of the SDOF system. Thus the regression equation of the ADRS is derived. The authors then proposed a seismic design method named force-displacementbased seismic design method of a single-column $\mathrm{RC}$ pier, by using the derived regression equation. The force-displacement-based seismic design method is one of the capacity spectrum methods proposed by Fajfar and by which the RC pier is designed so as to satisfy both its target strength and target displacement. And the design results for a single-column RC pier by the proposed method are compared with the ones by the current ductility design method of the Japanese Specifications. In consequence, it is found that the proposed method requires more ductility of the pier than the current method when the target strength of the proposed method and the design seismic force in the current ductility design method are the same and that, when the target response displacement of the both methods is almost the same, the proposed method requires more lateral capacity. Therefore the proposed force-displacement-based seismic design method can be a safer seismic design method of the RC pier.

The outline of this study is as follows.

\section{FORCE-DISPLACEMENT-BASED DE- SIGN}

Here, the capacity spectrum method, which is the basis of the force-displacement-based seismic design method proposed in this study, is briefly explained. Then the ADRS and the capacity spectrum of a structure required for the capacity spectrum method are simply described.

\section{(1) Capacity spectrum method}

In the capacity spectrum method, the seismic safety for both the force and displacement of a structure are verified concurrently, by the graph transaction as shown in Fig.1, comparing the capacity (allowable) values of acceleration and displacement with their demand (response) values. The capacity spectrum in Fig.1 is obtained by dividing the load $\left(Q^{*}\right)$ of load-displacement $\left(Q^{*}-D^{*}\right)$ relation by the equivalent mass $m^{*}$ for the equivalent SDOF system of a target structure which will be described in 2.(3). That is, the capacity spectrum method is a design method to confirm that the lateral capacity (allowable acceleration $S_{\mathrm{a}}$ ) of the designed structure exceeds the target strength (response acceleration $S_{a}{ }^{\prime}$ ), i.e., $S_{a} \geq S_{a}$ ' and that the target (response) displacement $\left(S_{d}\right)$ is almost equal to the allowable displacement $\left(S_{d}{ }^{\prime}\right)$, i.e., $S_{d}{ }^{\prime} \cong S_{d}$, by using the ADRS corresponding to the input earthquake motion for design. Furthermore, the allowable acceleration $S_{a}$ and displacement $S_{d}{ }^{\prime}$ in Fig.1 and in the text are obtained, respectively, by dividing the lateral capacity $\left(Q^{*}\right)$ of the designed struc-

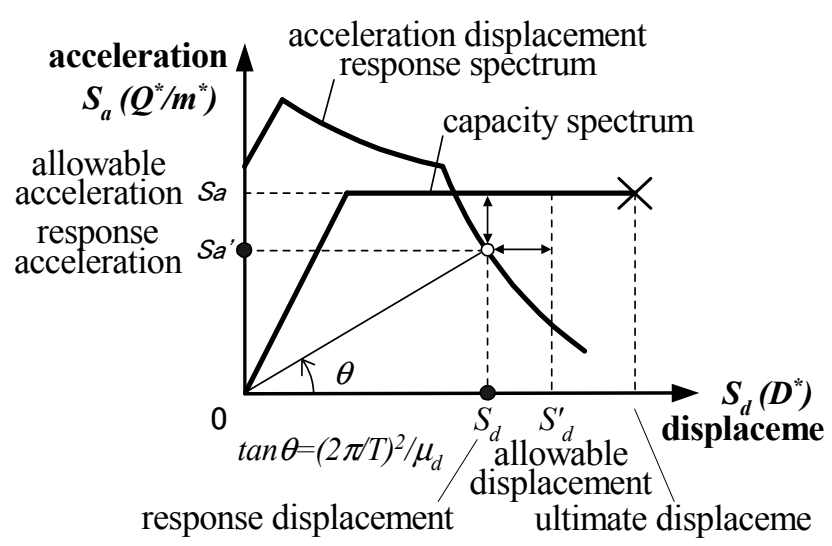

Fig.1 Capacity spectrum method 
ture by equivalent mass $\left(m^{*}\right)$, i.e., $S_{a}=Q^{*} / m^{*}$, and by multiplying the allowable displacement ductility factor $\mu_{a}$ by the yield displacement $\delta_{y}$, of the designed structure, i.e., $S_{d}{ }^{\prime}=\mu_{a} \times \delta_{y}$. Also the $S_{a}$ ' and $S_{d}$ indicate the response (target) acceleration and the response (target) displacement which are specified by the ADRS.

\section{(2) ADRS (Acceleration displacement response spectrum)}

The ADRS, which is the basis of the capacity spectrum method described in section (1), is the spectrum plotting the relation between the spectral acceleration $S_{a}{ }^{\prime}$ on vertical axis and displacement $S_{d}$ on horizontal axis. In this relation between the $S_{a}$, and $S_{d}$ defined by equation (3), the natural period $T$ of a structure can be obtained by equation (4) if the value of gradient $\theta$ of the line which connects the demand point of the structure and the origin is known, as illustrated in Fig. 1.

$$
\begin{gathered}
S_{d e}=\frac{1}{\omega_{0}^{2}} S_{a e}=\frac{T^{2}}{4 \pi^{2}} S_{a e} \\
S_{a}^{\prime}=S_{a e} \cdot R_{r} \\
S_{d}=\mu_{d} R_{r} S_{d e} \\
=\mu_{d} R_{r} \frac{T^{2}}{4 \pi^{2}} S_{a e}=\mu_{d} \frac{T^{2}}{4 \pi^{2}} S_{a}^{\prime} \\
\tan \theta=\frac{S_{a}^{\prime}}{S_{d}}=\frac{1}{\mu_{d}}\left(\frac{2 \pi)^{2}}{T}\right)
\end{gathered}
$$

in which $S_{a e}, S_{d e}, S_{a}$ ' and $S_{d}$ are the response spectral values of the elastic acceleration, pseudo elastic displacement, inelastic acceleration and inelastic displacement, respectively, and $\omega_{0}, R_{r}$ and $\mu_{d}$ are the natural circular frequency of the structure, required yield strength ratio (inverse number of the reduction factor) and displacement ductility factor, respectively.

Consequently, the ADRS can be obtained by the elastic acceleration response spectrum $S_{a e}$ through the required yield strength ratio $R_{r}$ (See 3. (2)) and the displacement ductility factor $\mu_{d}$. As will be described in 4. (1), the Level 2 earthquake motions used in this study are simulated so as to conform their elastic acceleration response spectra to the standard ones for dynamic analysis of the Japanese Specifications (See Fig.4). In this study, therefore, the value of the standard acceleration response spectrum of the Japanese Specifications is directly

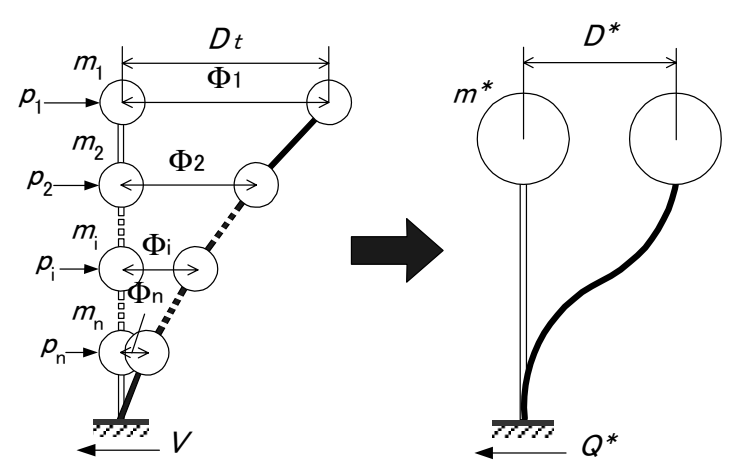

Fig.2 Multi degree of freedom system and equivalent single degree of freedom system

used for elastic spectral response acceleration $S_{a e}$ in equations $(1) \sim(3)$.

\section{(3) Capacity spectrum ${ }^{8)}$}

The capacity spectrum in Fig.1 required for the capacity spectrum method can be obtained by the following procedure.

1) First model the target structure into multi degree of freedom (MDOF) system as shown in Fig.2.

2) Next carry out the Push-Over (elastic-plastic) analysis of the MDOF system by the use of static load $p_{i}(i=1-n)$ with constant load ratio which is properly assumed ${ }^{9)}$ by the first mode shape, mass $\left(m_{i}\right)$ ratio of the system or the like.

3) Obtain the relation between the total shearing force $V=\Sigma p_{i}$ and the displacement $D_{t}$ of the characteristic point of the MDOF system by using the results of Push-Over analysis, and decide the deformation shape ratio $\Phi_{i}$ of the system (See Fig.2) corresponding to the representative point on the $V$ - $D_{t}$ curve (e.g. at the yield point of the MDOF system).

4) Obtain the mass $m^{*}$ and load $Q^{*}$ - displacement $D^{*}$ relation of the equivalent SDOF system by the use of $\boldsymbol{\Phi}_{i}, D_{t}, m_{i}$ and $p_{i}$.

5) Finally, linearly approximate the obtained $Q^{*}$ $D^{*}$ relation adequately, then obtain the capacity spectrum by dividing the load $Q^{*}$ of the linearly approximated $Q^{*}-D^{*}$ curve by the mass $m^{*}$.

In this study, however, the above-mentioned transformation is not employed, since the single-column RC pier that is chosen as the target of this study is modeled to the SDOF system in the Japanese Specifications. Therefore the capacity spectrum is obtained directly, by dividing the load of the load-displacement relation, obtained by the Push- Over analysis of the ductility design method in the Japanese Specifications, by the equivalent 
mass.

\section{DAMAGE INDEX $D$ AND REQUIRED YIELD STRENGTH RATIO $R_{r}$}

\section{(1) Damage index $D$}

In recent years, various indexes for evaluating the seismic damage of a structure quantitatively, that is, the damage indexes have been proposed. In this study Park-Ang damage index $D^{10)}$, which is often quoted due to the fact that the index is based on many experiment results and the fact that the mathematical expression is simple and manageable, is modified so that the value of $D$ may be negative under elastic response, and may be positive only under inelastic response as in equation (5). Then the damage controlled ADRS, described in the next 3. (2), is obtained by using the modified index (hereafter referred to as the modified Park-Ang damage index).

$$
D=\frac{\left(\mu_{d}-1\right)+\beta \cdot \mu_{h}}{\mu_{u}-1}
$$

in which $\beta$ is a positive coefficient which depends on the cross section characteristics of a $\mathrm{RC}$ member, and $\mu_{d}, \mu_{h}$ and $\mu_{u}$ are the displacement ductility factor, energy ductility factor and ductility capacity defined by the following equation, respectively.

$$
\mu_{d}=x_{\max } / x_{y}, \mu_{h}=E_{h} /\left(Q_{y} \cdot x_{y}\right), \mu_{u}=x_{u} / x_{y}
$$

in which $x_{\max }, x_{y}$ and $x_{u}$ in equation (6) are the maximum response displacements, yield displacement and ultimate displacement, respectively. $E_{h}$ and $Q_{y}$ are the absorbed hysteretic energy and yield strength.

\section{(2) Required yield strength ratio $R_{r}$}

One of the important parameters which control the damage of a structure under severe earthquake motions is the yield strength ratio $R^{11), 12)}$ defined by equation (7).

$$
R=Q_{y} / Q_{e \max }=x_{y} / x_{e \max }
$$

in which $Q_{e \max }$ and $x_{e \text { max }}$ are the maximum response restoring force and maximum response displacement when regarding the structure as an elastic sys- tem.

In this study, the value of $R$ by which the value of damage index $D$ in equation (5) becomes equal to its required value $D_{r}$ (the value which specifies a certain damage condition of the structure) is defined as the required yield strength ratio $R_{r}{ }^{12)}$ for the $D_{r}$, and the $R_{r}$ value is obtained by repeating the inelastic energy response analysis in which the value of $R$ is fluctuating. Then the spectral value of acceleration response $S_{a}$ ' is calculated by substituting the standard spectral value of acceleration response $S_{a e}$ of the Japanese Specifications, as above-mentioned, and the value of $R_{r}$ into equation (2). Also the spectral value of displacement response $S_{d}$ is calculated by substituting the calculated $S_{a}$ ' and the displacement ductility factor $\mu_{d}$ which correspond to the $R_{r}$ into equation (3). Therefore, the ADRS obtained in this study is damage controlled spectrum such that the degree of damage of the SDOF structure under Level 2 earthquake motions is equal to the damage condition specified by the required value $D_{r}$ of the modified Park-Ang damage index $D$.

\section{INPUT EARTHQUAKE MOTION AND STRUCTURAL CHARACTERRISTICS}

\section{(1) Input earthquake motion}

The seismic damage of a structure is affected not only by its structural characteristics but also by the characteristics of an input earthquake motion. In this study, therefore, in order to maintain the generality of analytic results, 72 simulated earthquake motions (acceleration waves) are generated ${ }^{13), 14)}$ so as to conform their elastic acceleration response spectra to the standard ones of the Level 2 earthquake motions for dynamic analysis specified in the Japanese Specifications ${ }^{1)}$, and the 72 acceleration waves are used as the input earthquake motions. On that occasion, for each soil condition of soft soil, moderate soil and stiff soil (hereafter referred to as the Group I soil, Group II soil and Group III soil, respectively), the authors simulated every 12 wave for three different magnitude $M=8.0,8.2$ and 8.4 with the epicenter distance $\Delta$ of $100 \mathrm{~km}, 150 \mathrm{~km}$, $200 \mathrm{~km}$ and $250 \mathrm{~km}$ in plate boundary earthquakes (hereafter referred to as the Type I earthquakes) and for three different magnitude $M=7.0,7.2$ and 7.4 with the epicenter distance $\Delta$ of $5 \mathrm{~km}, 10 \mathrm{~km}, 20 \mathrm{~km}$ and $30 \mathrm{~km}$ in inland earthquakes (hereafter referred to as the Type II earthquakes). In a time history response analysis, however, the duration of these simulated earthquake motions is unified to be 81.92 
seconds including the part with strong motion. An example of the acceleration waveform of the simulated earthquake motions is shown in Fig.3, and the comparison between the targeted acceleration response spectra of the Japanese Specifications and those of simulated earthquake motions each of which correspond to the targeted one is shown in Fig.4, respectively.

\section{(2) Structural characteristics}

In this study, as a fundamental research, elastic perfectly plastic bi-linear model with plastic rigidity ratio $\gamma=0.0$ is used as the restoring force characteristics of the SDOF structure, following the ductility design method for the single-column RC piers in the Japanese Specifications. As for the dumping factor $h$, natural period $T$ and ductility capacity $\mu_{u}$ of the structure, the values shown in Table 1 are employed. Also the value of $D_{r}=0.4$, as shown in Table 1, is adopted as the required value of the damage index $D$ in equation (5), and the hysteretic damage of the structure is considered by the use of mean value of the positive coefficient $\beta=0.15$ in equation (5).

In addition, the relation between the value of damage index $D$ and the damage condition of a structure is not necessarily clear. In this study, however, the authors regard $D_{r}=0.4$ which is close to the repairable limit 0.36 , for the time being, as the equivalent of the damage condition (repairable damage) of the important bridges (hereafter referred to as the Type B bridges) for the Level 2 earthquake motions in the Japanese Specifications, by referring to the relation of Geobarah et al. as shown in Table 2.

\section{(3) Analytic method}

In this study, the above-mentioned required yield strength ratio $R_{r}$ (See 3. (2)) of all the combinations of every input earthquake motion described in section (1) and every value of structural characteristics

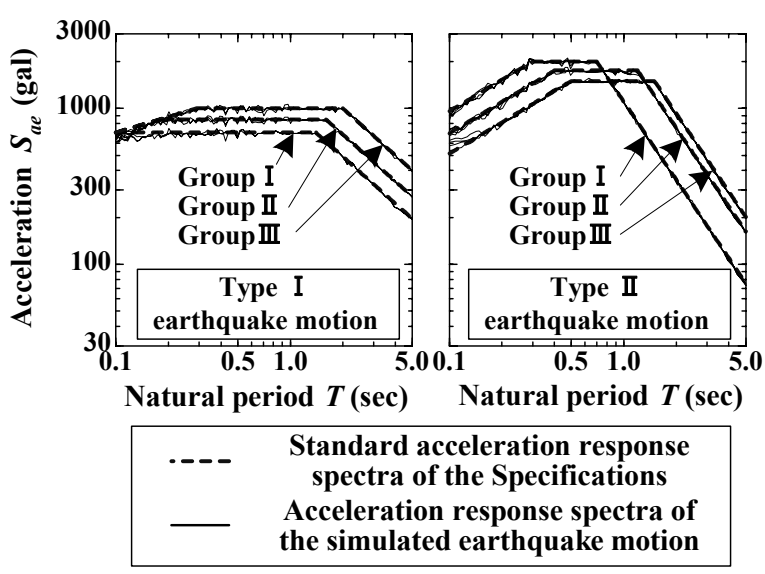

Fig.4 Acceleration response spectra

Table 1 Structural characteristics

\begin{tabular}{|ll||l|}
\hline Dumping factor & $h$ & 0.05 \\
\hline Plastic rigidity ratio & $\gamma$ & 0.00 \\
\hline \multirow{2}{*}{ Natural period } & $T$ & $\begin{array}{l}30 \text { values within the range } \\
\text { of } 0.1 \quad \text { to } 3.0 \quad \text { seconds } \\
\text { changing by } 0.1 \text { second }\end{array}$ \\
\hline Ductility capacity & $\mu_{u}$ & $\begin{array}{l}1.00 \text { (elastic response) } \\
1.5,2.0,3.0,4.0,6.0,8.0\end{array}$ \\
\hline $\begin{array}{l}\text { Required value of Park- } \\
\text { Ang damage index D }\end{array}$ & $D_{r}$ & 0.40 \\
\hline Positive coefficient & $\beta$ & 0.15 \\
\hline
\end{tabular}

Table 2 Mutual relation between damage condition and modified Park-Ang damage index $D$

\begin{tabular}{|l|c|}
\hline \multicolumn{1}{|c|}{ Damage condition } & Damage index \\
\hline \hline Elasticity limit & $\mathbf{0 . 0 8}$ \\
\hline Minor damage limit & $\mathbf{0 . 1 8}$ \\
\hline Repairable limit & $\mathbf{0 . 3 6}$ \\
\hline Collapse & $\mathbf{0 . 6 0}$ \\
\hline
\end{tabular}

stated in section (2), is obtained by inelastic energy response analysis. On that occasion the well-known equation of motion and energy response equation as shown in equations (8) and (9) are used, and the natural circular frequency $\omega_{0}=\left(k_{0} / m\right)^{1 / 2}$, (here the $k_{0}$ is the elastic rigidity of the bi-linear model), is
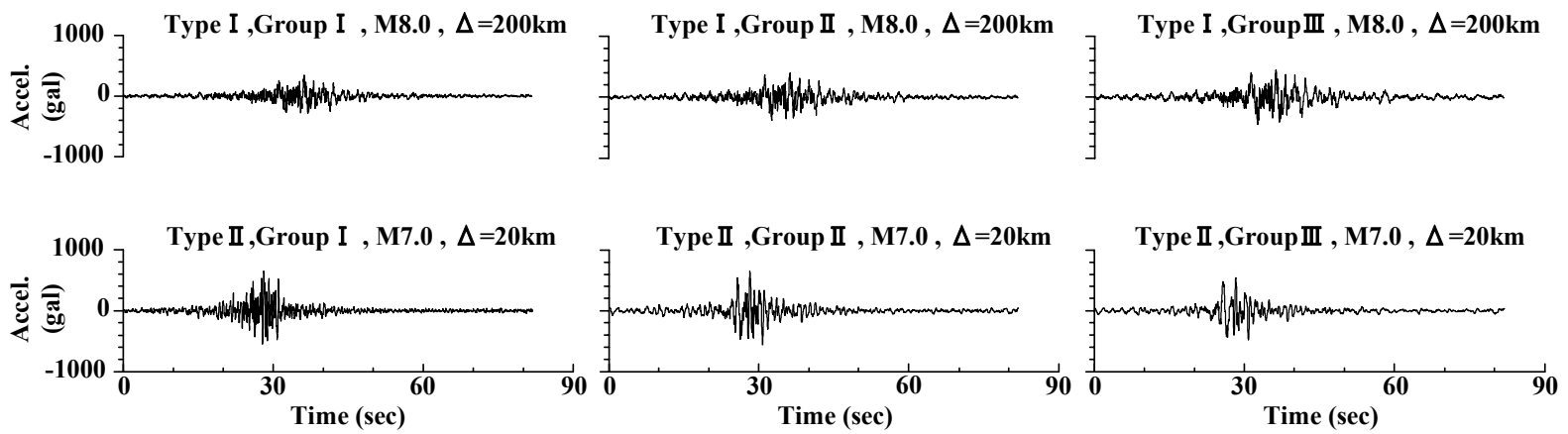

Fig.3 Acceleration waveform of simulated earthquake motion 
kept constant during the hysteretic vibration. The equation of motion in (8) is solved by the use of linear acceleration method with the constant time increment $d t=0.005$ seconds. Then the displacement ductility factor $\mu_{d}=x_{\max } / x_{y}$ is calculated from the obtained maximum response displacement $x_{\max }$. Also the absorbed hysteretic energy $E_{h}=\int Q(x) d x$ in equation (9) is calculated by numerical integration, making use of the response value of the each time step which is obtained by solving the equation (8), and after calculating the energy ductility factor $\mu_{h}=$ $E_{h} /\left(Q_{y} \cdot x_{y}\right)$ the value of damage index $D$ is obtained by equation (5).

$$
\begin{gathered}
m \ddot{x}+c \dot{x}+Q(x)=-m \ddot{x}_{0} \\
m \int \ddot{x} d x+c \int \dot{x} d x+\int Q(x) d x=-m \int \ddot{x}_{0} d x
\end{gathered}
$$

in which $\ddot{x}, \dot{x}$ and $x$ are relative acceleration, velocity and displacement, respectively, and $\ddot{x}_{0}, m$ and $Q(x)$ are acceleration of input earthquake motion, mass, and restoring force, respectively. And $c$ $\left(=2 h \omega_{0} m\right)$ is dumping coefficient.

\section{ADRS AND ITS REGRESSION EQUA- TION}

In order to carry out the seismic design of a structure by using the force-displacement-based seismic design method described in chapter 2., it is necessary to prepare the regression equation for the ADRS. In this study, therefore, the ADRS for all combinations of each input earthquake motion and each value of structural characteristics of elastic perfectly plastic bi-linear model described in 4. (1) and (2) is obtained by inelastic energy response analysis, and the mean spectral value and standard deviation $\sigma$ for every 12 simulated earthquake motion mentioned above, is calculated. Then the regression equation for the spectrum obtained by adding the standard deviation $\sigma$ to the mean spectrum (hereafter referred to as the $($ mean $+\sigma)$ spectrum) is derived. In this chapter, the analytic results relating to the derivation of the regression equation, derived regression equation and the $($ mean $+\sigma)$ spectrum are described and illustrated.

\section{(1) Comparison of analytic result}

Fig.5 shows the comparison of the 12 ADRS (the thin lines) of the elastic perfectly plastic bi-linear model, for every 12 simulated earthquake motion of each earthquake Type and soil Group, together with their mean spectrum (the broken line) and the $($ mean $+\sigma)$ spectrum (the thick line) in the case of dumping factor $h=5 \%$, value of the required damage index $D_{r}=0.4$, positive coefficient $\beta=0.15$ and ductility capacity $\mu_{u}=4.0$. In addition, the marks $\bigcirc$, $\triangle, \square$ and $\nabla$ plotted on the (mean $+\sigma$ ) spectrum in the figure indicate each demand (spectral acceleration and displacement) which correspond to the natural period $T=0.5,1.0,1.5$ and 2.0 seconds, respectively, for reference. It is written also that the coefficient of variation for the mean value of every 12 simulated earthquake motion is only 0.2 (most are 0.1 ) at the most, and it is relatively small, though the coefficient varies to some extent depending on the ductility capacity $\mu_{u}$, earthquake Type and soil Group.

It is found in Fig.5 that the two or three spectra among the ones of 12 simulated earthquake motions take larger spectral value than that of the $($ mean $+\sigma)$ spectrum for whole natural period range considered in this analysis. Notably the values of some spectra are considerably higher than the value of the $($ mean $+\sigma)$ spectrum in the range of the natural period $T=1.0$ (mark $\triangle$ ) 1.5 seconds (mark $\square$ ) of the soil Groups II and III for Type II earthquake motion. Therefore, the $($ mean $+\sigma)$ spectrum is not necessarily the safest spectrum. In this study, however, the regression equation for this $($ mean $+\sigma)$ spectrum is derived for the time being, and the spectrum obtained by the regression equation is used as the ADRS in the force-displacement-based seismic design method described in Chapter 2.

Next Fig.6 compars the effect of the difference in ductility capacity $\mu_{u}(=1.0,2.0,4.0$ and 8.0$)$ on the ADRS, i.e., on the $($ mean $+\sigma)$ spectrum in the case of each earthquake Type and soil Group, and the marks $O, \triangle, \square$ and $\nabla$ in the figure indicate the demand corresponding to the natural period $T=0.5,1.0$, 1.5 and 2.0 seconds, respectively, as same as in Fig. 5.

From Fig.6 it is found that the spectral value of acceleration becomes smaller as the value of ductility capacity $\mu_{u}$ gets larger, not regarding the earthquake Type and soil Group. This is due to the fact that the value of required yield strength at which the damage of the structure reaches a certain limit state (here the state of required value of damage index $D_{r}=0.4$ ) remains small in the structure with a larger value of $\mu_{u}$ and higher ductility compared with the one which has a smaller value of the $\mu_{u}$. Meanwhile the spectral value of displacement varies depending on the earthquake Type and soil Group and the value of ductility capacity $\mu_{u}$. Namely the spectral 

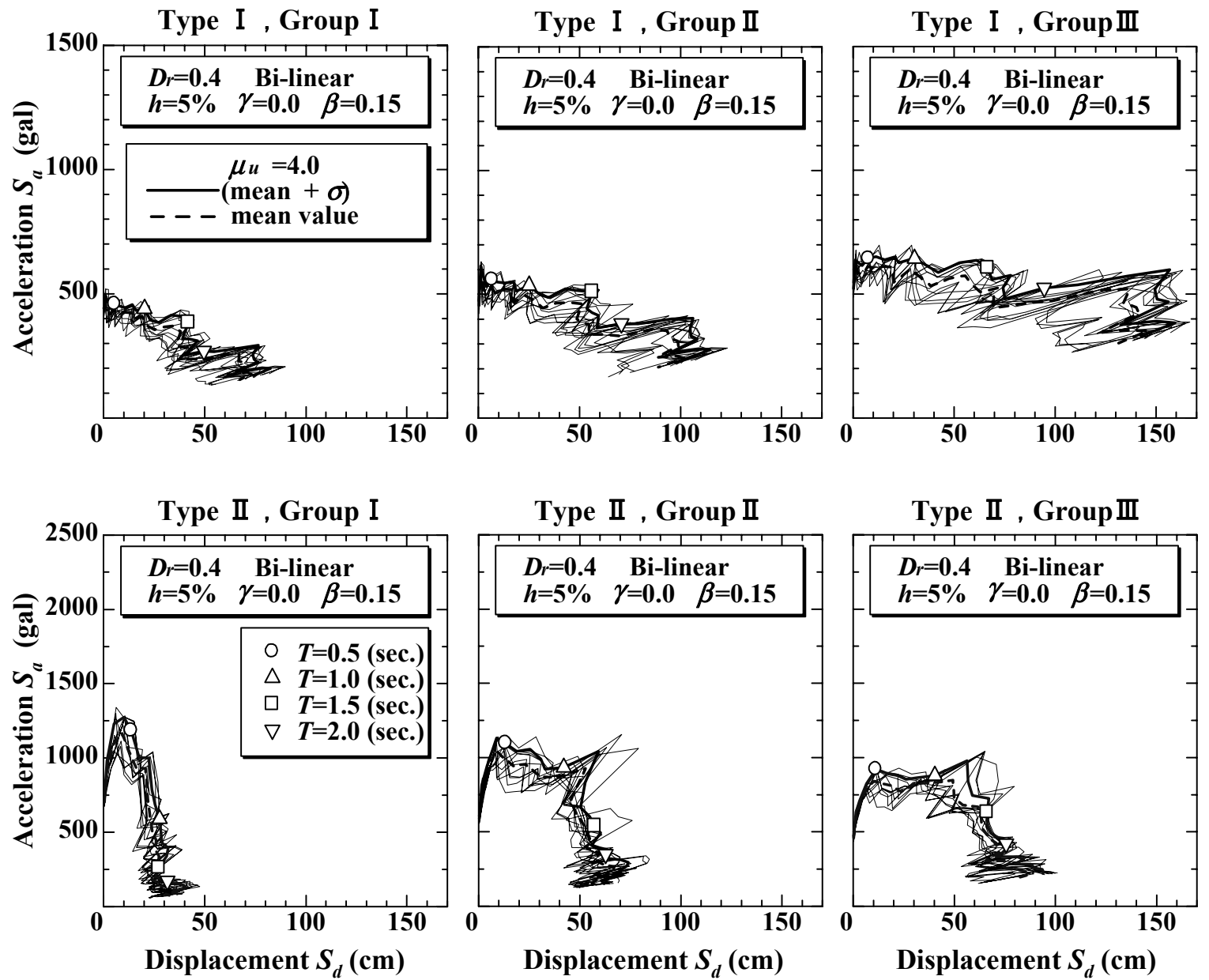

Fig.5 Comparison of ADRS for each 12 wave and for the (mean $+\sigma)$ ADRS

value in Type I earthquake motion increases as the value of the $\mu_{u}$ becomes greater up to the natural period $T=1.0$ second (up to the marks $\bigcirc$ and $\triangle$ in the figure) in the case of soil Groups I and II, and up to 1.5 seconds (up to the mark $\square$ ) in soil Group III. As to Type II earthquake motion, in this connection, the range of the natural period $T$ in which the similar tendency is shown gets up to $0.5 \mathrm{sec}-$ onds (up to the mark $O$ ) narrower in soil Groups I and II, and up to 1.0 second (up to the mark $\triangle$ ) narrower in soil Group III. However, such a small and large constant relation of spectral displacement due to the value of the $\mu_{u}$ gradually disappears in the natural period range over the above-mentioned range both in Type I and Type II earthquake motions. Namely the form of the ADRS becomes complex when $T \geq 1.5 \sim 2.0$ seconds in Type I earthquake motion, and when $T \geq$ about 1.0 1.5 seconds in Type II earthquake motion, though the range of $T$ depends on the soil Group.

Next in Type I earthquake motion the spectral value of acceleration increases almost evenly as the soil condition becomes softer from Group I to Group III for all the ductility capacity $\mu_{u}$ as same as the standard acceleration response spectra $S_{a e}$ of the Japanese Specifications (See Fig.4) to which the acceleration response spectra of simulated earthquake motions are conformed. On the contrary, except for the range of $T=0.5 \sim 1.5$ seconds, the spectral value in Type II earthquake motion decreases in a period range shorter than the excepted one ( $T=0.5 \sim 1.5$ seconds) as the soil condition gets softer. On the other hand the spectral value tends to increase in the range of $T$ longer than the above-excepted range. Also the spectral value of displacement in Type I earthquake motion increases as the soil condition becomes softer in the whole natural period range considered in this analysis, regardless of the value of ductility capacity $\mu_{u}$. Such tendency is more remarkable as the natural period $T$ becomes longer. Also the similar tendency as in Type I earthquake motion is found even in Type II earthquake motion when the natural period $T \geq 1.0 \sim 1.5$ seconds, though the adverse result is 

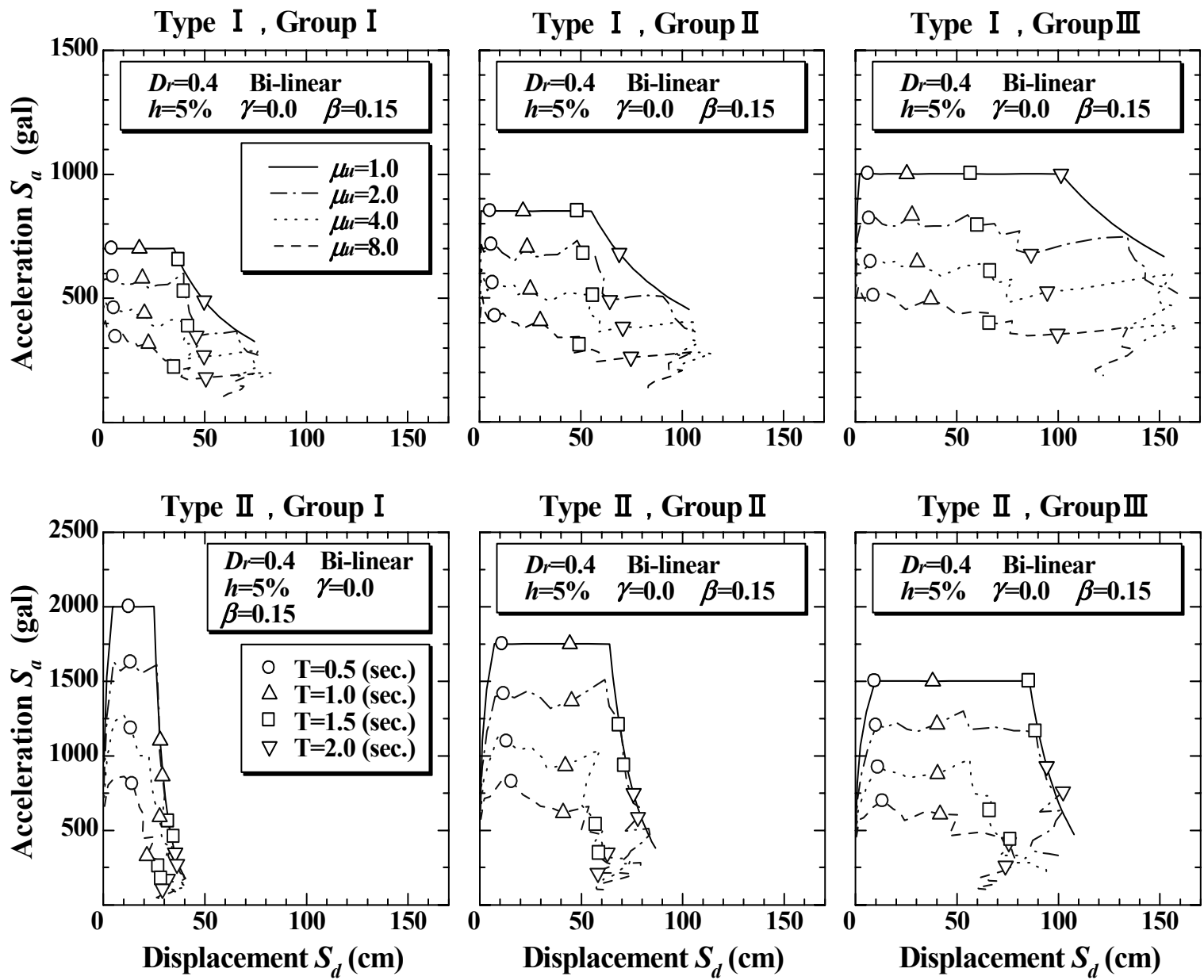

Fig.6 Comparison of effect of difference in ductility capacity $\mu_{u}$ on the (mean $+\sigma$ ) ADRS

seen when $T \leq 0.5$ seconds. And when the natural period $T \leq$ about 1.5 seconds the spectral value of displacement in Type II earthquake motion becomes larger compared with the one in Type I earthquake motion. However, such a small and large relation of spectral displacement is not clear when $T \geq$ about 1.5 seconds.

\section{(2) Derivation method of regression equation}

The form of inelastic ADRS varies depending on the Type of earthquake motion, Group of soil condition and value of the ductility capacity $\mu_{u}$ as shown in Fig.6. Also the form becomes considerably complex when the natural period $T \geq 1.5 \sim 2.0$ seconds. Therefore, it is unfavorable to employ this ADRS directly as the spectrum for seismic design. On that account, in this study, the mean value of the required yield strength ratio $R_{r}$ for every 12 simulated earthquake motion is first obtained considering the fact that the relation between above-mentioned equation (2) and equation (3), that is, the spectral value of the inelastic acceleration response $S_{a}$ ' can be obtained if the required yield strength ratio $R_{r}$ and the spectral value of the elastic acceleration response $S_{a e}$ are known and the spectral value of the inelastic displacement response $S_{d}$ can be obtained by the spectral values of the $S_{a}$ ' and the displacement ductility factor $\mu_{d}$. And in order to derive the safety side regression equation of the ADRS for design, the regression equation of the (mean $+\sigma$ ) spectrum for the $R_{r}$ is derived after obtaining the $($ mean $+\sigma)$ value by adding the standard deviation $\sigma$ to the mean value of the $R_{r}$. Then deriving the regression equation of the mean spectrum of displacement ductility factor $\mu_{d}$, the ADRS for seismic design corresponding to the $($ mean $+\sigma)$ value is obtained by using these regression equations and the standard acceleration response spectrum $S_{a e}$ of the Japanese Specifications (See equations (2) and (3)). The results derived are as follows:

\section{a) Regression equation of $\boldsymbol{R}_{r}$}

As seen from equation (2), the required yield strength ratio $R_{r}$ also varies depending on the 
earthquake Type, soil Group and value of the ductility capacity $\mu_{u}$ as same as the ADRS in Fig.6. Therefore, in this study, the regression equation of the (mean $+\sigma$ ) spectrum of the $R_{r}$ for each combination of the earthquake Type and soil Group is derived as mentioned above. The results are as shown in equations (10) and (11).

[Type I earthquake motion]

$$
\begin{aligned}
R_{r}(T)= & f\left(\mu_{u}, T\right) \\
= & \left(C_{0} / \mu_{u}^{2}+C_{1} / \mu_{u}+C_{2}\right) \\
& +\left(C_{3} / \mu_{u}^{2}+C_{4} / \mu_{u}+C_{5}\right) \cdot \ln (T)
\end{aligned}
$$

[Type II earthquake motion]

$$
\begin{aligned}
R_{r}(T)= & f\left(\mu_{u}, T\right) \\
= & \left(C_{0} / \mu_{u}^{2}+C_{1} / \mu_{u}+C_{2}\right) / T^{2} \\
& +\left(C_{3} / \mu_{u}^{2}+C_{4} / \mu_{u}+C_{5}\right) / T \\
& +\left(C_{6} / \mu_{u}^{2}+C_{7} / \mu_{u}+C_{8}\right)
\end{aligned}
$$

in which $C_{0} \sim C_{8}$ in equations (10) and (11) are the regression coefficients for each earthquake Type and soil Group as shown in Table 3.

\section{b) Regression equation of $\boldsymbol{\mu}_{\boldsymbol{d}}$}

As seen from equation (3), in order to obtain the regression equation of the inelastic displacement response spectra $S_{d}$, the regression equation of the displacement ductility factor $\mu_{d}$ which correspond to the $R_{r}$ is required in addition to the inelastic acceleration response spectra $S_{a}$ ' or the required yield strength ratio $R_{r}$ obtained in sub-section a) and the regression equation of the standard acceleration response spectra $S_{a e}$ of the Japanese Specifications. In this study, therefore, the regression equation targeting the mean value of the $\mu_{d}$ for every 12 simulated earthquake motion is also derived as follows.

$$
\begin{aligned}
\mu_{d}(T)= & \left(E_{0} \cdot \mu_{u}+E_{1}\right) \cdot T \\
& +\left(E_{2} \cdot \mu_{u}+E_{3}\right)
\end{aligned}
$$

in which the regression coefficients $E_{0} \sim E_{3}$ in equation (12) are as in Table 4, respectively, corre-

\begin{tabular}{|c|c|c|c|c|c|c|}
\hline & \multicolumn{3}{|c|}{ Type I } & \multicolumn{3}{|c|}{ Type II } \\
\hline & Group I & Group II & Group III & Group I & Group II & Group III \\
\hline $\bar{C}_{0}$ & "-0.686 & "-0.649 & "-0.590 & "0.001 & $\begin{array}{c}-0.007 \\
\end{array}$ & -0.011 \\
\hline$C_{1}$ & 1.403 & 1.344 & 1.267 & 0.002 & 0.016 & 0.021 \\
\hline$C_{2}$ & 0.275 & 0.296 & 0.317 & -0.002 & -0.008 & -0.010 \\
\hline$C_{3}$ & -0.199 & -0.220 & -0.241 & 0.075 & 0.160 & 0.199 \\
\hline$C_{4}$ & 0.310 & 0.340 & 0.386 & -0.157 & -0.325 & -0.386 \\
\hline$C_{5}$ & -0.114 & -0.124 & -0.149 & 0.081 & 0.161 & 0.187 \\
\hline$C_{6}$ & - & - & - & -0.916 & -0.919 & -0.933 \\
\hline$C_{7}$ & - & - & - & 1.855 & 1.917 & 1.939 \\
\hline$C_{8}$ & - & - & - & 0.056 & 0.002 & -0.010 \\
\hline
\end{tabular}
sponding to each combination of earthquake Type and soil Group.

\section{c) Comparison of regression and analytic results}

Fig.7 shows the comparison of regression result of the $($ mean $+\sigma)$ spectrum of the ADRS and the analytic one of the corresponding spectrum to the
Table 3 Regression coefficients $C_{0} \sim C_{8}$ of $R_{r}$ (Equations (10), (11))

Table 4 Regression coefficients $E_{0} \sim E_{3}$ of $\mu_{d}$ (Equation (12))

\begin{tabular}{|l|c|c|c|c|c|c|}
\hline & \multicolumn{3}{|c|}{ Type I } & \multicolumn{3}{c|}{ Type II } \\
\cline { 2 - 7 } & Group I & Group II & Group III & Group I & Group II & Group III \\
\hline \hline$E_{0}$ & $\mathbf{0 . 0 0 2}$ & $\mathbf{0 . 0 0 0}$ & $-\mathbf{0 . 0 0 7}$ & $\mathbf{- 0 . 0 0 7}$ & $-\mathbf{0 . 0 1 6}$ & $\mathbf{- 0 . 0 2 5}$ \\
\hline$E_{1}$ & $\mathbf{0 . 0 0 6}$ & $\mathbf{0 . 0 0 8}$ & $\mathbf{0 . 0 2 0}$ & $\mathbf{0 . 0 2 0}$ & $\mathbf{0 . 0 2 2}$ & $\mathbf{0 . 0 4 0}$ \\
\hline$E_{2}$ & $\mathbf{0 . 0 0 6}$ & $\mathbf{0 . 2 6 5}$ & $\mathbf{0 . 2 8 0}$ & $\mathbf{0 . 2 6 4}$ & $\mathbf{0 . 2 8 8}$ & $\mathbf{0 . 2 9 9}$ \\
\hline$E_{3}$ & $\mathbf{0 . 7 8 0}$ & $\mathbf{0 . 7 7 0}$ & $\mathbf{0 . 7 4 4}$ & $\mathbf{0 . 7 7 4}$ & $\mathbf{0 . 7 4 3}$ & $\mathbf{0 . 7 2 6}$ \\
\hline
\end{tabular}

regression result in the case of ductility capacity $\mu_{u}$ $=2.0$ and 8.0 for each earthquake Type and soil Group. Here the regression result is obtained by substituting the regression equation of $R_{r}$ and $\mu_{d}$ derived in the above sub-sections a) and b) and the standard acceleration response spectrum $S_{a e}$ of the Japanese Specifications into equations (2) and (3).

It is found from Fig.7 that the regression result reproduces the analytic result relatively well except for the range of natural period $T \geq 1.5 \sim 2.0$ seconds in which the form of the ADRS becomes to be complicated.

\section{APPLICATION TO A SINGLE- COLUMN RC PIER}

Here, by using the regression equation of the ADRS derived in chapter 5., the design procedure of the capacity spectrum method targeting a single $\mathrm{RC}$ pier is indicated. In this method what is called force-displacement-based design method, it is required that the lateral capacity of the pier exceeds its target strength and the response displacement of the pier is almost equal to its target. And the results of the numerical calculations of each procedure in the design example of a single-column RC pier with the design condition, described in the next section (1), is shown. Then the final design results are tabulated and are discussed and compared with the results obtained by the ductility design method of the Japanese Specifications. 

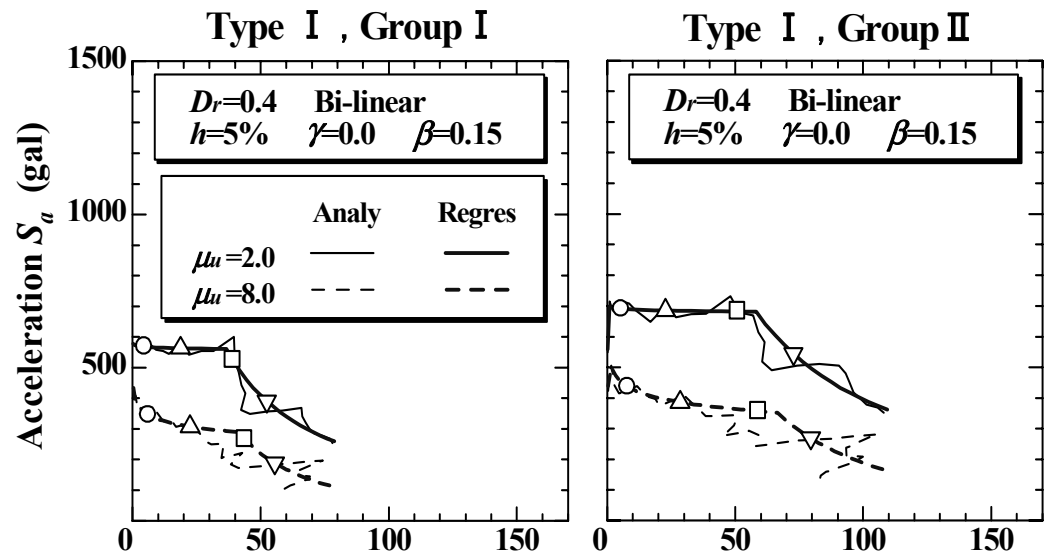

Type I , GroupIII
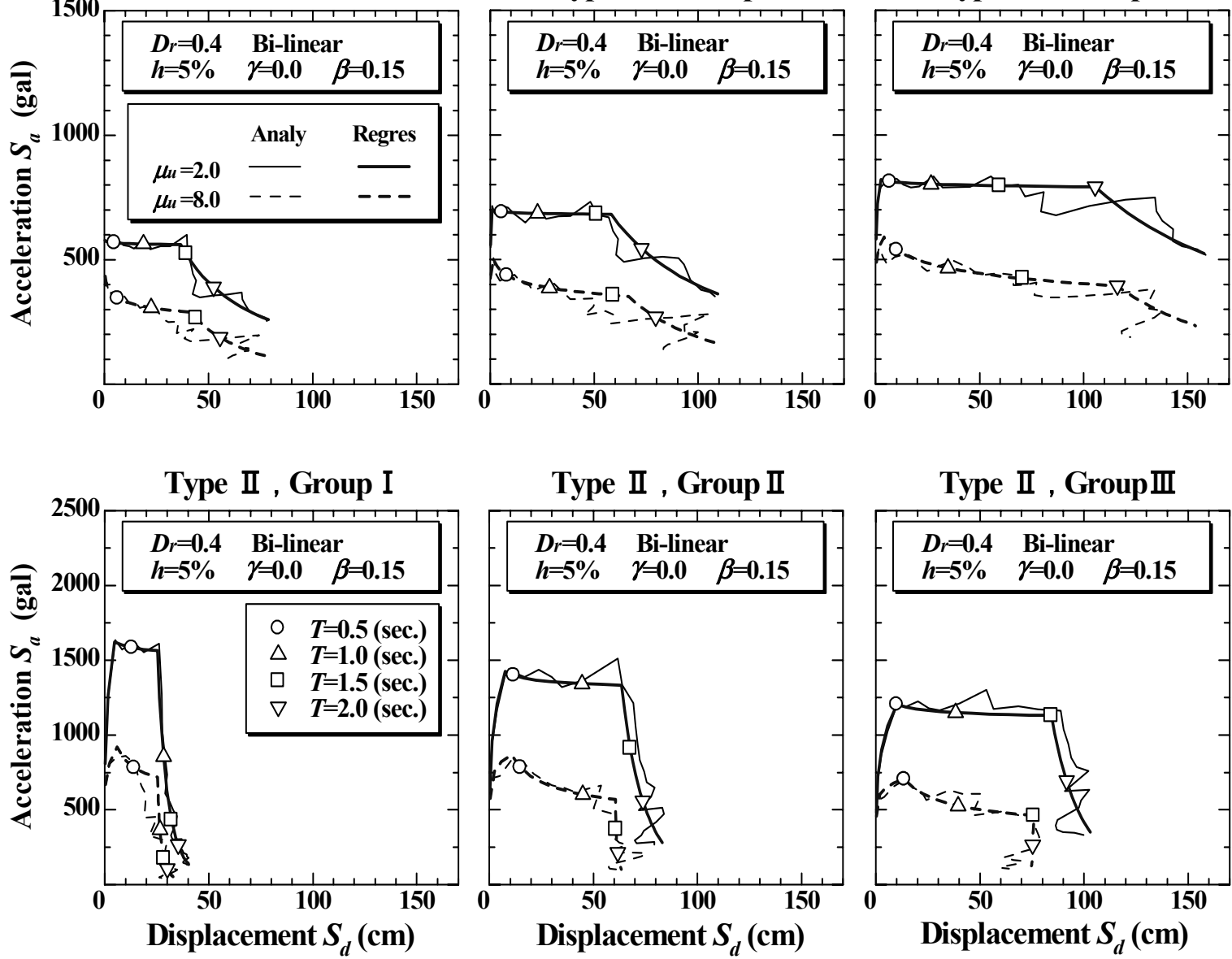

Fig.7 Comparison of regression result and analytic result

\section{(1) Design conditions}

The T-shaped single-column RC pier with circular cross section as shown in Fig.8 is employed as the target pier for design, and it is assumed that its superstructure is a simple girder bridge loaded with $\mathrm{B}$ live load (live load for important bridges). It also sets the foundation for the cast-in-place RC pile and the soil condition to be Group II, and the weight of superstructure, pier height and cross sectional diameter are set at $W_{u}=4900(\mathrm{kN})(500(\mathrm{tf})), h_{p}=6(\mathrm{~m})$ and $\phi=2.5(\mathrm{~m})$, respectively. Other shapes and sizes of the pier are shown in Fig.8. In addition, the strength and elastic modulus of concrete and reinforcing bar are set at normal values as below, and arrangement of the reinforcing bar is set to be double without a cutoff.

\section{[Concrete]}

Compressive strength $f_{c}{ }^{\prime}=2.058\left(\mathrm{MP}_{\mathrm{a}}\right):\left(210\left(\mathrm{kgf} / \mathrm{cm}^{2}\right)\right)$ Elastic modulus $E_{c}=2.303\left(\mathrm{GP}_{\mathrm{a}}\right):\left(2.35 \times 10^{5}\left(\mathrm{kgf} / \mathrm{cm}^{2}\right)\right)$

[Reinforcing bar (SD295)]

Yield strength $f_{y}=29.40\left(\mathrm{MP}_{\mathrm{a}}\right):\left(3000\left(\mathrm{kgf} / \mathrm{cm}^{2}\right)\right)$

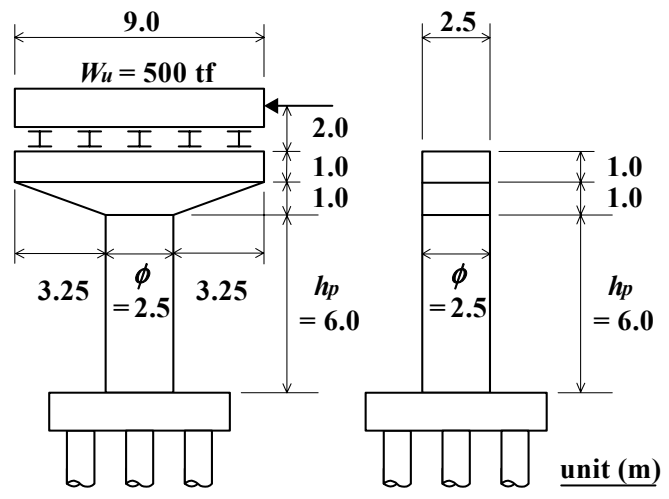

Fig.8 Shapes and sizes of designed pier

Elastic modulus $E_{s}=20.58\left(\mathrm{GP}_{\mathrm{a}}\right):\left(2.1 \times 10^{6}\left(\mathrm{kgf} / \mathrm{cm}^{2}\right)\right)$

(2) Design procedure of force-displacementbased design

a) Design procedure

Corresponding to the procedure 1) 9) of the design calculation flow shown in Fig.9, the explanation of the design procedure of the force-displace- 
ment-based design becomes as follows:

1) First, set the equivalent mass $m^{*}$ of the target pier (equivalent SDOF structure), target acceleration $S_{a}$ (target strength $F_{y}=m^{*} \cdot S_{a}$ ) and target displacement $S_{d}$ etc.

2) Next, assume the ductility capacity $\mu_{u 1}$ of the pier and describe the ADRS corresponding to this $\mu_{u 1}$ (See 5. (2))

3) Plot the target value $\left(S_{a}\right.$ and $\left.S_{d}\right)$ set in procedure 1) on this spectrum and calculate the gradient $\theta_{1}$ of the line connecting the point $\left(S_{a}\right.$ and $\left.S_{d}\right)$ to the origin from equation (4). Next calculate the elastic natural period $T_{1}$ which satisfies equations (4) and (12).

4) Obtain the required yield strength ratio $R_{r 1}$ by substituting the $\mu_{u 1}$ assumed in procedure 2) and $T_{1}$ obtained in procedure 3 ) into equations (10) or (11) depending on the Type of earthquake motion, and calculate the response acceleration value $S_{a 1}$ by substituting the obtained $R_{r 1}$ and the standard elastic response acceleration $S_{a e}\left(T_{1}\right)$ of the Japanese Specifications into equation (2). Then calculate the convergence determination error $\varepsilon_{S a 1}$ between this calculated $S_{a 1}$ and the target $S_{a}$ from equation (13), and proceed to procedure 5) if the error is within the allowable range (e.g. $\varepsilon_{S a i} \leq 1 \%$ ). Meanwhile, if the error is not within the range, move to procedure $\mathbf{6}$ ).

$$
\varepsilon_{\text {Sai }}=\frac{\left|S_{a}-S_{a i}\right|}{S_{a}} \times 100(\%) \quad(i=1,2 \cdots)
$$

in which $\varepsilon_{S a i}$ is the convergence determination error of the response acceleration value $S_{a i}$ of $i$ time repetition.

5) In the same way, calculate the maximum response value of displacement $S_{d 1}$ from equation (3), and obtain the convergence determination error $\varepsilon_{S d 1}$ between this $S_{d 1}$ and the target $S_{d}$ from equation (14). Then if the obtained $\varepsilon_{S d 1}$ is within the range of allowable error (e.g. $\varepsilon_{S d i} \leq 1 \%$ ), move to procedure 7). If not, proceed to procedure 6 ).

$$
\varepsilon_{S d i}=\frac{\left|S_{d}-S_{d i}\right|}{S_{d}} \times 100(\%) \quad(i=1,2 \ldots)
$$

in which $\varepsilon_{S d i}$ is the convergence determination error of the response displacement $S_{d i}$ of $i$ time repetition.

6) Calculate the ductility capacity $\mu_{u}$ ' which satisfies the relation of equation (2) by substituting the

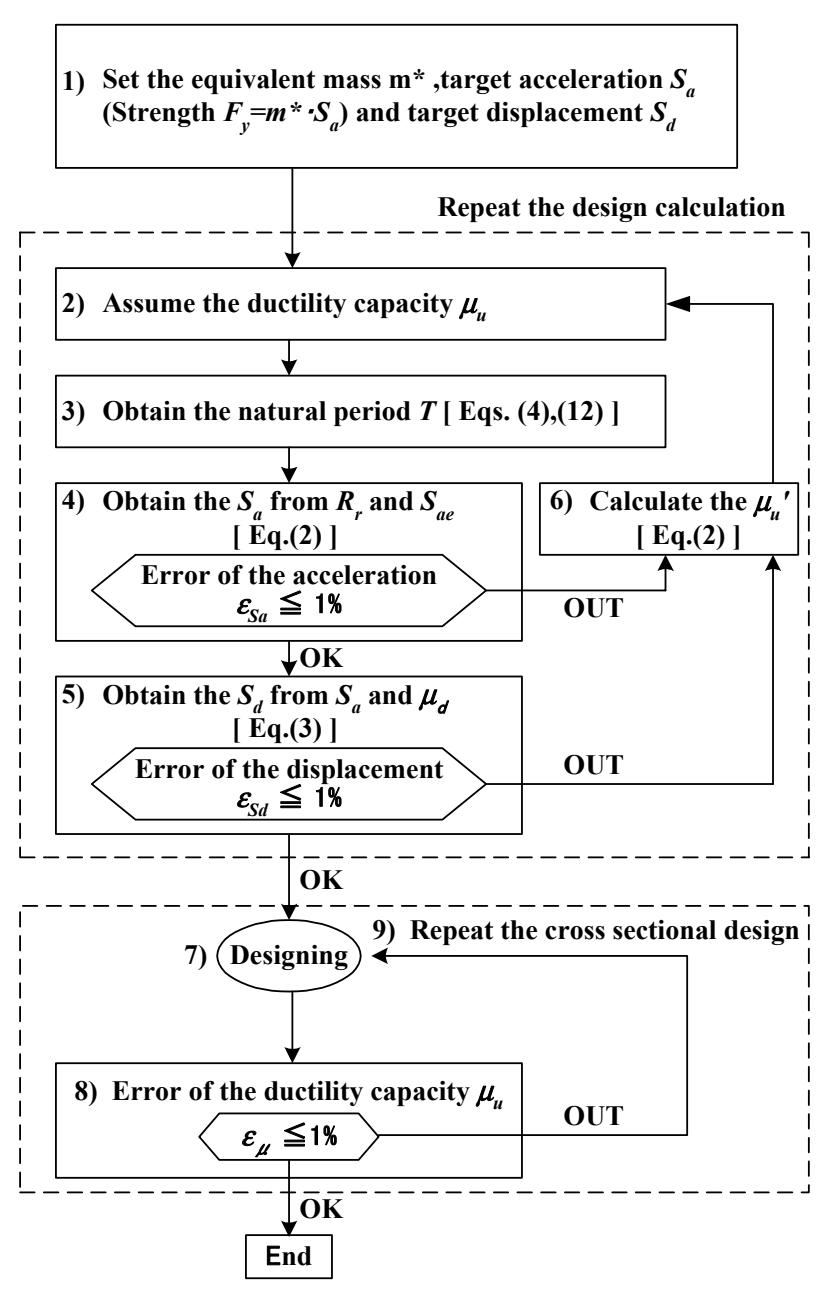

Fig.9 Design calculation flow

target acceleration $S_{a}$ for the $S_{a}$ ' of equation (2) and by substituting the natural period $T_{1}$ calculated in procedure 3 ) into the regression equations of $S_{a e}$ and $R_{r}$ (equation (10) or (11)) in the right side of the same equation. Then return to procedure 2) by setting this $\mu_{u}$ ' as the assumed value $\mu_{u 2}$ for the second time.

7) As in the ductility design method of the Japanese Specifications the ductility capacity $\mu_{u}$ is obtained as well as the amount of reinforcement etc. by making a cross sectional design so that the lateral capacity $F_{y}$ ' of the pier is equal to or larger than the target strength $F_{y}$ set in 1) (to be $F_{y}{ }^{\prime} \geq F_{y}$ ).

8) Obtain the convergence determination error $\varepsilon_{\mu}$ between the ductility capacity $\mu_{u i}$ assumed in procedure 2) and the value $\mu_{u}\left(=\mu_{u i}{ }^{\prime}\right)$ designed in procedure 7) from equation (15). Then finish the design calculation if the error is within the range of the allowable error (e.g. $\varepsilon_{\mu} \leq 1 \%$ ), regarding the ductility capacity of the designed pier reproduces the assumed value $\mu_{u i}$ in procedure 2), that is, the response displacement $S_{d i}$ of the designed pier becomes almost equal to the target displace- 
ment $S_{d}\left(S_{d} \cong S_{d}\right)$. Meanwhile, proceed to procedure 9) if the error $\varepsilon_{\mu}$ is not within the allowable range.

$$
\varepsilon_{\mu}=\frac{\left|\mu_{u i}-\mu_{u i}^{\prime}\right|}{\mu_{u i}} \times 100(\%) \quad(i=1,2 \cdots)
$$

in which $\varepsilon_{\mu}$ is the convergence determination error of the ductility capacity, and $\mu_{u i}$ and $\mu_{u i}$ ' are $i$ time ductility capacity of the pier assumed in procedure 2) and the ductility capacity obtained by the design calculation in 7), respectively.

9) Repeat the design calculation of the cross section, changing the amount of main and tai reinforcements, and decide the cross section (amount of the reinforcement) such that $F_{y} \geq F_{y}$ and the convergence determination error $\varepsilon_{\mu}$ in equation (15) is within the range of the allowable error.

\section{b) Design example}

In accordance with design procedures 1) 9) described in sub-section a), the design calculation for the single-column RC pier with the shape and sizes as shown in Fig.8 and with the design conditions described in section (1) is carried out to satisfy the values of the target acceleration $S_{a}=800$ (gal) and displacement $S_{d}=15(\mathrm{~cm})$ subjected to Type II earthquake motion whose effect on the damage of the pier dominates that of Type I earthquake motion. The numerical results in each of the above-mentioned design procedures for this example are shown as follows:

[The first time]

1) Equivalent mass $m^{*}=582.3\left(\mathrm{kN} \cdot \mathrm{s}^{2} / \mathrm{m}\right)$

Target acceleration $S_{a}=800$ (gal)

$$
\left[F_{y}=4658.5(\mathrm{kN})\right]
$$

Target displacement $S_{d}=15(\mathrm{~cm})$

2) Ductility capacity $\mu_{u 1}=6.5$

3) Elastic natural period $T_{1}=0.54$ (second)

4) Response acceleration $S_{a 1}=820.6$ (gal)

Convergence determination error

$$
\varepsilon_{\text {Sa1 }}=2.57 \%>1.0 \% \quad \Rightarrow \text { OUT move to 6) }
$$

6) Ductility capacity

$$
\mu_{u 1}{ }^{\prime}=6.95
$$

Return to 2) setting this $\mu_{u 1}$ ' as the assumed value $\mu_{u 2}$ of the second time.

[The second time]

2) Ductility capacity $\mu_{u 2}=6.95$

3) Elastic natural period $T_{2}=0.52$ (second)

4) Response acceleration $S_{a 2}=807.1$ (gal)

Convergence determination error

$$
\varepsilon_{S a 2}=0.89 \%<1.0 \% \quad \Rightarrow \text { OK } \quad \text { move to 5) }
$$

5) Response displacement $S_{d 2}=15.2(\mathrm{~cm})$

Convergence determination error

$$
\varepsilon_{S d 2}=1.04 \%>1.0 \% \quad \Rightarrow \text { OUT move to 6) }
$$

6) Ductility capacity

$$
\mu_{u 2}{ }^{\prime}=7.12
$$

Return to 2) setting this $\mu_{u 2}$ ' as the assumed value $\mu_{u 3}$ of the third time.

[The third time]

2) Ductility capacity $\mu_{u 3}=7.12$

3) Elastic natural period $T_{3}=0.52$ (second)

4) Response acceleration $S_{a 3}=803.1$ (gal)

Convergence determination error $\varepsilon_{S a 3}=0.38 \%<1.0 \% \Rightarrow \mathrm{OK} \quad$ move to 5)

5) Response displacement $S_{d 3}=15.1(\mathrm{~cm})$

Convergence determination error

$$
\varepsilon_{S d 2}=0.39 \%<1.0 \% \quad \Rightarrow \mathrm{OK} \quad \text { move to } 7 \text { ) }
$$

7) Repeat the design calculation of the cross section and decide the amount and arrangement of main and tie reinforcements (See Table 5) so that the lateral capacity $P_{a}\left(=F_{y}{ }^{\prime}\right)$ becomes equal to or larger than the target strength $F_{y}=4658.5(\mathrm{kN})$. Lateral capacity

$$
P_{a}=4669.2(\mathrm{kN})>F_{y}=4658.5(\mathrm{kN}) \Rightarrow \mathrm{OK}
$$

8) Confirm whether the error $\varepsilon_{\mu}$ in equation (15) between the ductility capacity $\mu_{u 3}{ }^{\prime}=7.11$ of the designed pier (See Table 5) and the assumed value $\mu_{u 3}=7.12$ of the third time in 2) is within the range of the allowable error.

Convergence determination error

$$
\varepsilon_{\mu}=0.21 \%<1.0 \% \Rightarrow \mathrm{OK} \text { end of design }
$$

In addition, Fig.10 shows the comparison of the ADRS corresponding to the ductility capacity $\mu_{u 3}=$ 7.12 assumed in the third repetition and the capacity spectrum of the pier. From this figure it is found that the designed pier almost reproduces the target acceleration [strength] $S_{a}=800$ (gal) $\left[F_{y}=4658.5\right.$ $(\mathrm{kN})]$ and the target displacement $S_{d}=15(\mathrm{~cm})$.

\section{c) Comparison with the ductility design method}

As is well known, the ductility design method of Japanese Specifications is not the method to satisfy both targets of acceleration (strength of the pier) and displacement concurrently, unlike the forcedisplacement-based seismic design method described in sub-section a). And the design example by the proposed method, presented in $\mathbf{b}$ ), is the result obtained by use of the design ADRS which satisfies the required value $D_{r}=0.4$ of the modified Park-Ang damage index $D$, regarding that this required value $D_{r}=0.4$ is equivalent to the recoverable damage for the Level 2 earthquake motion of Type 
B bridges in the ductility design method of Japanese Specifications, for the time being, as described in 4. (2). In addition, the value $D_{r}=0.4$ used in this study is slightly different from the repairable limit 0.36 proposed by Geobarah et al. (See Table 2), also the value of Geobarah et al. is the one for the $\mathrm{RC}$ building structure and not the value for the RC pier targeted in this study. Therefore it is not necessarily said that there is a good corresponding relation between the degree of damage for $D_{r}=0.4$ and the degree of repairable damage for the Level 2 earthquake motion of Type B bridges in the ductility design method of Japanese Specifications. From these points above, it is a little unreasonable to compare the results by the above-mentioned force-displacement-based design method with the results obtained by the ductility design method of the Japanese Specifications. However, in order to examine the qualitative difference between the two design methods, the design of the pier by the ductility design method is attempted in these cases; i) the case giving $S_{a}=800 \quad$ (gal) $\left[F_{y}=4658.5(\mathrm{kN})\right]$ as the design acceleration (design strength) and ii) the case giving the allowable design displacement as $\delta_{a}=\mu_{a} \cdot \delta_{y}=15(\mathrm{~cm})$, targeting the pier with the same design condition, shape and size as in the design example presented in sub-section b). Here, the case i) is employed to examine the difference between the results of both designs when the lateral capacity $P_{a}$ of the ductility design method is almost equal to that of the force-displacement-based design method, and in case ii) where it is employed to examine the difference between the two results when the allowable displacement $\delta_{a}=\mu_{a} \cdot \delta_{y}$ of the former almost equals the target displacement $S_{d}$ of the latter.

The comparison of the difference in the design results, that is, the difference in the lateral capacity, displacement, amount of reinforcement, etc., between the two design methods are shown in Fig.10 and Table 5, respectively.

As seen from the figure and table the ductility capacity $\mu_{u}$ decreases considerably in the ductility design method of Japanese Specifications compared with the force-displacement-based seismic design method in this study, and the allowable displacement $\delta_{a}=\mu_{a} \cdot \delta_{y}$ which is considered to be equivalent to the target (response) displacement $S_{d}$ in this method also decreases slightly, when the lateral capacity $P_{a}$ is almost the same. Relating to this, the amount of main reinforcement increases and the amount of the tie reinforcement decreases.

The above-mentioned result in which the allow-

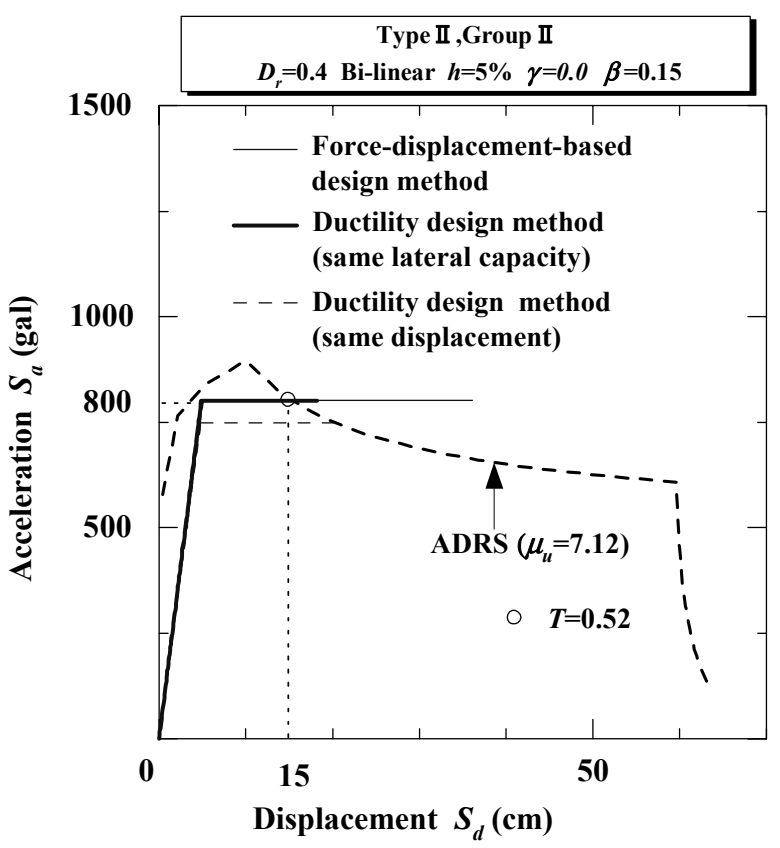

Fig.10 Comparison of capacity spectra between forcedisplacement-based design method and ductility design method

able displacement $\delta_{a}$ etc. decrease in the ductility design method seems to be caused by the obtaining method of the design seismic force. That is, in the ductility design method, the equivalent lateral seismic coefficient $k_{h e}$ is calculated by the use of allowable displacement ductility factor $\mu_{a}$ and the equal energy assumption. Then the design seismic force is obtained by multiplying the seismic coefficient $k_{h e}$ by the equivalent weight $W$. Therefore, if the equivalent weight (mass) and the design seismic force are given initially as in the comparison here, the value of the allowable displacement ductility factor $\mu_{a}$ is inevitably decided by these values and the ductility capacity $\mu_{u}$ is also decided (through the safety factora ).

Furthermore, when the displacement is almost the same, the lateral capacity $P_{a}$ and the ductility capacity $\mu_{u}$ decrease and the amount of both the main and tie reinforcements also decrease in the ductility design method compared with the force-displacement-based design method. This is due to the obtaining method of the design seismic force, as mentioned above.

From the above-mentioned results, it is found that the force-displacement-based seismic design method proposed in this study requires more toughness (ductility) after yielding if the target strength (lateral capacity) is almost the same and requires more lateral capacity if the response displacement is almost the same, compared with the 
Table 5 Comparison of design results between force-displacement-based design method and ductility design method

\begin{tabular}{|c|c|c|c|c|c|}
\hline & & & $\begin{array}{c}\text { Force - } \\
\text { displacement-based } \\
\text { design method }\end{array}$ & $\begin{array}{c}\text { Ductility design } \\
\text { method } \\
\text { (same lateral capacity) }\end{array}$ & $\begin{array}{c}\text { Ductility design } \\
\text { method } \\
\text { (same displacement) }\end{array}$ \\
\hline \multirow{5}{*}{\multicolumn{2}{|c|}{ 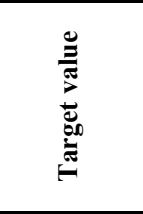 }} & Equivalent mass $m *\left(\mathrm{kN} \cdot \mathrm{s}^{2} / \mathrm{m}\right)$ & 582.3 & 582.3 & 582.3 \\
\hline & & Target acceleration $S_{a}(\mathrm{gal})$ & 800 & $800^{1)}$ & - \\
\hline & & Target strength $F_{y}(\mathrm{kN})$ & 4658.5 & $4658.5^{2)}$ & 一 \\
\hline & & Target displacement $S_{d}(\mathrm{~cm})$ & 15 & - & $15^{3)}$ \\
\hline & & Ductility capacity (assumed value) $\mu_{u}$ & 7.12 & - & - \\
\hline \multirow{7}{*}{\multicolumn{2}{|c|}{ 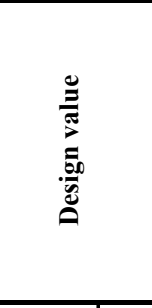 }} & Ductility capacity $\mu_{u}$ & 7.11 & 3.74 & 4.19 \\
\hline & & Elastic natural period $T^{*}(\mathrm{sec})$ & 0.52 & 0.49 & $\mathbf{0 . 5 0}$ \\
\hline & & \begin{tabular}{|ll} 
Yield displacement $\delta_{y}(\mathrm{~cm})$ \\
\end{tabular} & 5.04 & 4.86 & 4.80 \\
\hline & & \begin{tabular}{|l|} 
Allowable displacement \\
ductility factor $\mu_{a}=S_{d} / \delta_{y}$ \\
\end{tabular} & 2.98 & 2.83 & 3.13 \\
\hline & & Lateral capacity $P_{a}(\mathrm{kN})$ & 4669.2 & 4662.6 & 4354.0 \\
\hline & & \begin{tabular}{|ll} 
Yield acceleration & $S_{a y}(\mathrm{gal})$ \\
\end{tabular} & $\mathbf{8 0 1 . 8}$ & 800.7 & 747.7 \\
\hline & & Allowable displacement $\quad(\mathrm{cm})$ & 15.1 & 13.8 & 15.0 \\
\hline \multirow{8}{*}{ 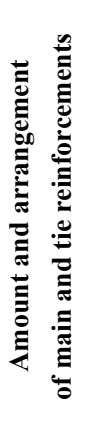 } & \multirow{5}{*}{ 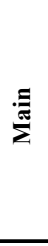 } & Diameter & D35 & D35 & D35 \\
\hline & & Pitch (mm) & 80 & 77 & 87 \\
\hline & & Number of the bar & $80 \times 2$ & $83 \times 2$ & $75 \times 2$ \\
\hline & & Concrete cover (mm) & $115 \sim 225$ & $115 \sim 230$ & $110 \sim 210$ \\
\hline & & Main reinforcement ratio $\rho_{l}(\%)$ & 3.12 & 3.24 & 2.92 \\
\hline & \multirow{3}{*}{$\cong$} & Diameter & D22 & D16 & D19 \\
\hline & & Pitch (mm) & $101 \times 2$ & $101 \times 2$ & $133 \times 2$ \\
\hline & & $\begin{array}{l}\text { Tie reinforcement } \\
\text { volume ratio } \rho_{s}(\%)\end{array}$ & 1.35 & 0.69 & 0.76 \\
\hline
\end{tabular}

$\begin{array}{lll}\text { 1) Design (target) acceleration } & \text { 2) Design (target) seismic force } & \text { 3) Allowable design (target) displacement }\end{array}$

ductility design method of the Japanese Specifications. It is said, therefore, that the proposed method in this study is a safer design compared with the ductility design method of the Japanese Specifications.

\section{CONCLUSIONS}

In this study, the acceleration displacement response spectrum (ADRS) used in the capacity spectrum method is obtained by the inelastic response analysis and after examining the analytic result the regression equation of the $($ mean $+\sigma)$ spectrum for the required yield strength ratio $R_{r}$ and the mean spectrum of the displacement ductility factor $\mu_{d}$ are derived for each combination of the earthquake Type and soil Group. Then, the inelastic ADRS for design which satisfies the required value $D_{r}=0.4$ of the modified Park-Ang damage index $D$, by using these regression equations of the $R_{r}$ and $\mu_{d}$ and the standard acceleration response spectra $S_{a e}$ for the Level 2 earthquake motion of the Japanese Specifications is derived. And the capacity spectrum method, that is, the force- displacement-based seismic design method for a single-column RC pier is proposed by use of the derived ADRS, and the qualitative difference in the design results, between the proposed method and the ductility design method of the Japanese Specifications, are compared and discussed.

The results obtained in this study are summarized as follows:

1) From the relation of equations (1) (3), the regression equation of the ADRS for design is derived by use of the regression equations of the required yield strength ratio $R_{r}$, displacement ductility factor $\mu_{d}$ and standard acceleration response spectra $S_{a e}$ of the Japanese Specifications. Then the desirable result of the ADRS with relatively high accuracy is obtained in the range of natural period $T \leq$ about 1.0 second which is supposed to correspond with the range of natural period $T$ of a large number of single-column $\mathrm{RC}$ piers, though the accuracy decreases slightly in the longer range of natural period $T>1.0 \sim 1.5$ seconds of the structure.

2) A single-column RC pier which satisfies the target strength $F_{y}=4658.5(\mathrm{kN})\left[S_{a}=800(\mathrm{gal})\right]$ and the 
target displacement $S_{d}=15(\mathrm{~cm})$ is designed by the force-displacement-based seismic design method by use of the ADRS for design derived in this study. Comparing the design results with the ones by the ductility design method of the Japanese Specifications in which the design seismic force is set to be equal to the target strength $F_{y}$, the force-displacement-based seismic design method proposed in this study requires greater toughness (ductility) after yielding compared with the ductility design method due to the obtaining method of the design seismic force in the ductility design method described in 6. c). This result means that the proposed design method is the safer method compared with the ductility design method.

3) Similarly, the design by the ductility design method is carried out so that the allowable displacement $\delta_{a}=\mu_{a} \cdot \delta_{y}$ is equal to the target displacement $S_{d}=15(\mathrm{~cm})$ in the force- displacement-based seismic design method. Comparing the results with the ones by the force-displacement-based design of this study, the proposed method requires more lateral capacity and ductility capacity than the ones by the ductility design method due to the same reason as described above in 2). This also means the proposed method is the safer design.

In addition, the above-mentioned results in 2) and 3) are the ones in the case when the repairable damage in the ductility design method of the Japanese Specifications for Type B bridges is regarded to be almost equal to the damage corresponding to the value of the modified Park-Ang damage index $D=0.4$ as described above. Therefore, the design results by the proposed method could be different depending on the damage condition (seismic performance) of the structure to be assumed. Thus, the authors think it is necessary from now on to make similar comparisons and to make consideration as in this study which are based on the many design results obtained by use of the regression equation of the ADRS for the different required $D_{r}$ values of the modified Park-Ang damage index $D$.

ACKNOWLEDGMENT: This study is supported in part by Ministry of Education, Culture, Sports, Science and Technology, Grant-in-Aid for Scientific Research (No.13650523, 2001-2003). And the authors would like to express our gratitude to $\mathrm{Mr}$. Miki, Y. for his assistance in preparing the figures etc. in this study when he was a graduate student of the University of Tokushima

\section{REFERENCES}

1) Japan Road Association: Design specifications of highway bridges, part V seismic design, (in Japanese),1999.12

2) Kowalsky, M.J., Priestley, M.J.N. and A. Macrae, G.A.: Displacement-based design of bridge columns in seismic regions, Earthquake engineering and structural dynamics, Vol.24, pp.1623-1643, 1995.

3) Calvi, G.M. and Kingsley, G.R. : Displacement-based seismic design of multi-degree-of-freedom bridge structures, Earthquake engineering and structural dynamics, Vol.24, pp.1247-1266, 1995.

4) Miranda, E. and Ruiz-Garcia, J. : Evaluation of approximate methods to estimate maximum inelastic displacement demands, Earthquake engineering and structural dynamics, Vol.28, pp.539-560, 2002.

5) Fajfar, P. : Capacity spectrum method based on inelastic demand spectra, Earthquake engineering and structural dynamics, Vol.28, pp.979-993, 1999.

6) Fajfar, P.: A nonlinear analysis method for performancebased seismic design, Earthquake Spectra, Vol.16, No.3, 2000.8 .

7) Japan Association for Building Research Promotion: Performance evaluation guideline of reinforced concrete building, Gihodo Shuppan, (in Japanese), 2000.8.

8) Krawinkler, H. and Seneviratna, G.D.P.K. : Pros and cons of pushover analysis of seismic performance evaluation, Engineering Structures, Vol.20, Nos 4-6, pp.1-12, 1998.

9) Sogabe, N., Hirao, K. and Nariyuki, Y.: A study on seismic damage analysis of MDOF structures by the use of equivalent SDOF model, Journal of Structural Engineering, Vol.46A, pp. 675-684, (in Japanese), 2000.3

10) Park, Y.J. and Ang, A.H-S. : Mechanistic seismic damage model for reinforced concrete, Journal of Structures Engineering, ASCE, Vol.111, No.4, pp.722-739, 1985.4.

11) Hirao, K., Sawada, T. and Nariyuki, Y.: Relationship between typical yield strength ratios used in earthquake response analysis, Journal of Structural Mechanics and Earthquake Engineering, JSCE, No.465/I-23, pp.159-162, (in Japanese), 1993.4.

12) Hirao, K., Sasada, S., Nariyuki, Y. Sasada, T. and Kawabata, S.: Required yield strength ratio spectrum and its application for verification of seismic safety of a structure excited by severe earthquake motions, Journal of Structural Mechanics and Earthquake Engineering, JSCE, No.525 / I-33, pp.213-225, (in Japanese), 1995.10.

13) Sawada, T. and Hirao, K.: A generation method of simulated earthquake complying with target response spectrum, Proceedings of the $17^{\text {th }}$ conference on earthquake engineering, JSCE, pp.49-52, (in Japanese), 1983.7. 
14) Sawada, T., Nagae, M. and Hirao, K.: A definition for duration of earthquake ground motion by phase differences and its statistical analysis, Journal of Structural Mechanics and Earthquake Engineering, JSCE, No.386/I-5, pp.373-382, (in Japanese), 1986.4.

15) Cosenza, E. and Manfredi, G.: Seismic Analysis of Degrading Models by Means of Damage Function Concept,
Nonlinear Seismic Analysis and Design of Reinforced Concrete Buildings, pp.77-93, 1992.

16) Geobarah, A., Aly, N. M. and El-Attar, M.: Seismic reliability assessment of existing reinforced concrete buildings, Journal of Earthquake Engineering, Vol.2, No.4, pp.569-592, 1998.

(Received September 12, 2003) 